\title{
Breastfeeding self-efficacy as a dominant factor affecting maternal breastfeeding satisfaction
}

\author{
Siti Nurbayanti Awaliyah ${ }^{1,2}$, Imami Nur Rachmawati ${ }^{3^{*}}$ and Hayuni Rahmah ${ }^{3}$ \\ From The 6th Biennial International Nursing Conference \\ Depok, Indonesia. 2-4 October 2017
}

\begin{abstract}
Background: One of the psychological benefits of breastfeeding for mothers and infants is to get the satisfaction of breastfeeding. Maternal breastfeeding satisfaction derives from the interaction and cooperation between mothers and their babies. This research aims to identify the maternal breastfeeding satisfaction and its influential factors.

Methods: This study applied a cross-sectional design. Two hundred four breastfeeding mothers after four until 8 months postpartum were recruited using cluster sampling methods. Respondents completed the questionnaire of Maternal Breastfeeding Evaluation Scale (MBES) to identify maternal breastfeeding satisfaction. Factors affecting maternal breastfeeding satisfaction were identified using the following instruments: Breastfeeding Knowledge Questionnaire was used to identify knowledge on lactation, Infant Feeding Attitude Scale (IIFAS) to identify attitude toward lactation, and the Breastfeeding Self-Efficacy Scale-Short Form (BSES-SF) to identify breastfeeding self-efficacy.

Result: We identified that $53.4 \%$ of the breastfeeding mothers had a high level of satisfaction. The results indicate that the household income, type of delivery, and breastfeeding self-efficacy was associated with breastfeeding satisfaction $(p<0.05)$. Breastfeeding self-efficacy is the most influential factors in maternal breastfeeding satisfaction (OR=16.64; Cl 95\% 7.65-35.94).

Conclusion: Breastfeeding satisfaction is the satisfying feeling obtained during breastfeeding resulting from cooperation between the mother and the infant to fullfil desires or needs. Education and promotion of breast milk and breastfeeding provided by professional healthcare providers encouraged the successful of breastfeeding programs. Assistance by a health care provider or breastfeeding counselor during the seven contacts breastfeeding initiated during pregnancy until after delivery should be applied so that the mother is informed about breastfeeding. Breastfeeding satisfaction can keep the mother from continuing to breastfeed her baby for up to 2 years or more.
\end{abstract}

Keywords: Breastfeeding, Breastfeeding self-efficacy, Maternal breastfeeding satisfaction

\section{Background}

The World Health Assembly (2012) supported a resolution for comprehensive implementation of nutritional targets for mothers, infants, and children, as ratified in the Global Nutrition Targets 2025 . Globally, only $38 \%$ of infants aged 0 to 6 months receive breast milk exclusively [1]. According to a

\footnotetext{
* Correspondence: inrachma@ui.ac.id

${ }^{3}$ Department of Maternity and Women's Health, Faculty of Nursing, Universitas Indonesia, Jalan. Prof. Dr. Bahder Djohan. Kampus UI Depok, Depok, West Java 16424, Indonesia

Full list of author information is available at the end of the article
}

report from the United Nations Children's Fund (UNICEF), Indonesia, only $42 \%$ of infants in Indonesia of up to 6 months old are exclusively breastfed [2]. The average duration of exclusive breast milk nutrition is only 1 to 2 months, with the rate of breastfeeding decreasing after 2 months of age. The average duration of breastfeeding wordwide is 20.5 months, and the average duration of exclusive breastfeeding in Indonesia is more than 3 months [3].

Several factors contribute to the low rate of exclusive breastfeeding. The healthcare and social care professionals

(c) The Author(s). 2019 Open Access This article is distributed under the terms of the Creative Commons Attribution 4.0 International License (http://creativecommons.org/licenses/by/4.0/), which permits unrestricted use, distribution, and 
sometines assume that mixed feeding practice is more advantageous that exclusive breasfeeding. The other factors include the absence of support for breastfeeding in the workplace, the advertising of formula, and lack of knowledge of the women, partners, family members, healthcare providers and policy makers about the appropriate methods for, and the risks associated with, non-exclusive breastfeeding [1].

In reality, many women experience difficulties in breastfeeding. For the majority, it is not easy or natural [4]. A majority of women consider initial breastfeeding to be a painful, difficult and challenging experience [5]. Failure in breastfeeding is not only related to feelings of guilt [6] but also to the diminishing of maternal identity [7].

Failure in breastfeeding usually derives from problems faced by mothers and infants [8]. Breastfeeding problems may often occur up to 2 weeks (51\%) and 6 weeks (49\%) after birth and the perception of the lack of breast milk is the most common problem faced. Problems of breastfeeding are related to feelings of satisfaction in breastfeeding mothers, and these have an impact on early breastfeeding. Maternal breastfeeding satisfaction is defined as the perception by mothers of personal satisfaction and success in breastfeeding. Duration of breastfeeding determines the level of satisfaction for mothers who exclusively breastfeed for up to 2 months (84.6\%) and 4 months (69.8\%), even though the duration is lower than the recommended 6 months [9].

Some factors related to the duration are age, education, employment, household income, parity, and delivery type [10]. Moreover, knowledge, attitude, self-efficacy, intention and social support mothers receive also affect satisfaction [11]. Studies regarding breastfeeding satisfaction need to be carried out in Indonesia. Such research is crucial as satisfaction can provide benefits, including mental health benefits, for mothers and infants. Regarding mental and emotional wellbeing, it is the case that stimulation of the hormone oxytocin, which occurs in mothers and infants during breastfeeding, creates a pleasant experience for both, and motivates mothers to continue breastfeeding.

\section{Methods}

This cross-sectional study aimed to determine the association between the dependent variable of breastfeeding satisfaction with independent variables of breastfeeding satisfaction factors consisting of age, education, employment, household income, parity, type of delivery, knowledge about breastfeeding, attitudes toward breastfeeding and breastfeeding self-efficacy of the mothers. A cluster sampling was applied in selecting 2478 breastfeeding mothers who spread over 62 Community Health Centers in Bandung, West Java, Indonesia. Primary sampling unit was two Community Health Centers, namely Pasir Kaliki and Babakan Sari. Secondary sampling units were breastfeeding mothers after 4 to 8 months of delivery. The inclusion criteria for the study were mothers who breastfeed their infant for 4-8 months after birth, marital status, and residence within a nuclear family. The exclusion criteria were mothers with physical problems such as bulbous nipples resulting from hypoplasia, or insufficient glandular. The other conditions, such as mothers who had a poor health condition and habitual smoking also were not included. This sampling method assigned 204 breastfeeding mothers from 34 Community Health Centers as respondents.

For measuring satisfaction was applied the Maternal Breastfeeding Evaluation Scale (MBFES) which developed by Leff, Jeffries, and Gagne (1994). MBES was designed to measure the positive and negative aspects of breastfeeding mothers to identify the importance of breastfeeding successful definition (Schlomer, Kemmere, \& Twiss, 1999). This tool was translated into Bahasa Indonesia and tested for validity and reliability using Cronbach's alpha, giving a value of 0.940 . Low satisfaction if the value is less than 115 , high satisfaction if the value is more than 116 . The following was adapted questionnaires procured in Bahasa Indonesia versions: Breastfeeding Knowledge Questionnaire developed by Brodribb, Fallon, Jackson, and Hegney (2008) for measuring knowledge about lactation, less knowledge if score $0-7$ and good knowledge if score 8-15. The Iowa Infant Feeding Attitude Scale (IIFAS) developed by Mora and Russel was used to measure attitude towards lactation. Negative attitude if the total score was less than 55 and a positive attitude if the total score was more than 55 . Breastfeeding Self-Efficacy Scale-Short Form (BSES-SF), developed by Bandura (1997) used to measure breastfeeding self-efficacy. BSES-SF is an excellent instrument for measuring breastfeeding self-efficacy and is considered appropriate for clinical use such as identifying high-risk breastfeeding mothers, assessing breastfeeding and cognition behaviors as individual strategies in building trust, and evaluate the effectiveness of various interventions and guidelines in development programs (Dennis, 2003). The Cronbach's alpha coefficient value for each instrument is $0.94,0.83,0.9$ and 0.87 respectively. Low self-efficacy if total score less than 55 and high self-efficacy if the total score is more than 56.

The study was conducted in Bandung, which is a large city functioning as one of the major economic, commercial and industrial cities in Indonesia and which has various problems resulting from urbanisation. High population density has been shown to be one of the causes of low breastfeeding exclusivity [12]. Breast milk provision in the province of West Java is $35.3 \%$, while the target agreed by the 2015 strategic development was 39\% [13].

Univariate analysis was used to describe the characteristics of the respondents. These characteristics include age, education, employment, household income, parity, 
and delivery type, together with knowledge about and attitude towards breastfeeding, and breastfeeding selfefficacy. A bivariate analysis was conducted using a chisquare test, to gain insight into the relationships between the respondents' characteristics, knowledge, attitudes and breastfeeding self-efficacy. The multivariate analysis used logistic regression testing to disclose the most dominant factors affecting maternal breastfeeding satisfaction.

\section{Results}

The majority of the respondents were $27-35$ years old (65.2\%) and had a high level of education (81.4\%). They were unemployed (93.1\%) and had incomes of less than IDR $2,850,000$, i.e., below the regional minimum wage level (75\%). The majority are multipara or a parent of multiple children (65.2\%). The most common type of delivery is normal per vaginal (85.3\%) (see Table 1). Table 2 shows that the majority of respondents claimed to have high maternal breastfeeding satisfaction (53.4\%) compared to the rest of the respondents with low satisfaction (46.6\%). The majority lacked knowledge on breastfeeding (64.2\%). More than half of the respondents had a negative attitude towards breastfeeding (52.9\%), but a majority had high self-efficacy (55.9\%). The information presented in Table 3 shows that household income, delivery type, and breastfeeding self-efficacy is associated to satisfaction in breastfeeding. The results in Table 4 show that the most dominant factor that affects maternal breastfeeding satisfaction is breastfeeding self-

Table 1 The Characteristics of the Respondents

\begin{tabular}{lll}
\hline Characteristics & Number & Percent \\
\hline Age & 71 & 34.8 \\
Young adult (17-25 years old) & 133 & 65.2 \\
$\quad$ Adult (26-35 years old) & & \\
Education & 38 & 18.6 \\
$\quad$ Low level of education (Primary, Middle) & 81.4 \\
High level of education (High School, College) & 166 & \\
Employment & & \\
Unemployed & 190 & 93.1 \\
Employed & 14 & 14 \\
Household Income (IDR) & & \\
Below Regional Minimum Wage & 153 & 75 \\
Above Regional Minimum Wage & 51 & 25 \\
Parity & & \\
Primipara & 71 & 34,8 \\
Multipara & 133 & 65.2 \\
Delivery Type & & \\
Major surgery & 30 & 14.7 \\
Normal (per vaginal) & 174 & 65.2 \\
\hline
\end{tabular}

Table 2 Maternal breastfeeding satisfaction, knowledge, attitude, and breastfeeding self efficacy

\begin{tabular}{|c|c|c|}
\hline Variables & Number & Percent \\
\hline \multicolumn{3}{|c|}{ Maternal breastfeeding satisfaction } \\
\hline Low & 95 & 46.6 \\
\hline High & 109 & 53.4 \\
\hline \multicolumn{3}{|c|}{ Knowledge regarding breastfeeding } \\
\hline Insufficient & 131 & 64.2 \\
\hline Sufficient & 73 & 35.8 \\
\hline \multicolumn{3}{|c|}{ Attitude toward breastfeeding } \\
\hline Negative & 108 & 52.9 \\
\hline Positive & 96 & 47.1 \\
\hline \multicolumn{3}{|c|}{ Breastfeeding Self-efficacy } \\
\hline Low & 90 & 44.1 \\
\hline High & 114 & 55.9 \\
\hline
\end{tabular}

efficacy $(\mathrm{OR}=16.6495 \%$ CI 7.6-35.9). Household income, education, attitude and delivery type are also factors that influence maternal breastfeeding satisfaction.

\section{Discussion}

\section{Maternal breastfeeding satisfaction}

The results indicate that the majority of the respondents (53.4\%) experience high maternal breastfeeding satisfaction. They breastfeed for 4 to 8 months after birth. The results of this study are in line with the previous cohort study which stated that the determinants factors of maternal breastfeeding satisfaction at 6 months after delivery are based on the duration of breastfeeding. Longer durations are reported to achieve a higher satisfaction [14]. Breastfeeding is a complex social behaviour, and the mother's perception of the success of breastfeeding cannot be entirely explained based on whether breastfeeding problems arise; mothers do gain satisfaction, but they also face problems arising from breastfeeding [15]. It is anticipated that high satisfaction leads to longer duration of breastfeeding [9] which in turn impacts on experience and practice with subsequent infants [16].

Gregory, Butz, Ghazarian, Gross, and Johnson mentioned that satisfaction associated with expectations when prenatal about the duration of breastfeeding. The study reported one-year postpartum, 34.7\% of the 1802 respondents had met prenatal expected breastfeeding duration, and $23.9 \%$ were still breastfeeding. $40.4 \%$ respondents reported being satisfied with the duration. But at 12 months postpartum more respondents said that their expectation had been fulfilled, and they are satisfied with the duration of breastfeeding. The results of this study indirectly illustrated that some of the respondents have breastfed for more than 6 months and meet the expectations of breastfeeding after childbirth [17]. 
Table 3 The association between the characteristics of the respondents, knowledge, attitude, breastfeeding self-efficacy, and maternal breastfeeding satisfaction

\begin{tabular}{|c|c|c|c|c|c|c|}
\hline \multirow[t]{3}{*}{ Independent Variables } & \multicolumn{3}{|c|}{$\begin{array}{l}\text { Content Variables } \\
\text { Maternal Breastfeeding Satisfaction }\end{array}$} & \multicolumn{2}{|c|}{ OR $(95 \% \mathrm{Cl})$} & \multirow[t]{3}{*}{$p$ Value } \\
\hline & \multicolumn{2}{|c|}{ High } & \multicolumn{2}{|l|}{ Low } & & \\
\hline & $\bar{n}$ & $\%$ & $\bar{n}$ & $\%$ & & \\
\hline \multicolumn{7}{|l|}{ Age } \\
\hline Young Adult & 40 & 56.3 & 31 & 43.7 & $1.83(1.02-3.28)$ & 0.058 \\
\hline Adult & 55 & 41.4 & 78 & 58.6 & & \\
\hline \multicolumn{7}{|l|}{ Education } \\
\hline Low & 21 & 55.3 & 27 & 44.7 & $1.65(0.80-3.38)$ & 0.234 \\
\hline High & 74 & 44.6 & 92 & 55.4 & & \\
\hline \multicolumn{7}{|l|}{ Employment } \\
\hline Unemployed & 91 & 47.9 & 99 & 52.1 & $2.30(0.70-7.56)$ & 0.262 \\
\hline Employed & 4 & 28.6 & 10 & 71.4 & & \\
\hline \multicolumn{7}{|l|}{ Household Income } \\
\hline Below Minimum & 81 & 52.9 & 72 & 47.1 & $2.97(1.49-5.94)$ & 0.003 \\
\hline Above Minimum & 14 & 27.5 & 37 & 72.5 & & \\
\hline \multicolumn{7}{|l|}{ Parity } \\
\hline Primipara & 33 & 46.5 & 38 & 53.5 & $0.99(0.56-1.77)$ & 1.000 \\
\hline Multipara & 62 & 46.6 & 71 & 53.4 & & \\
\hline \multicolumn{7}{|l|}{ Delivery Type } \\
\hline Major Surgery & 6 & 20 & 24 & 80 & $0.24(0.09-0.61)$ & 0.003 \\
\hline Normal (per vaginal) & 89 & 51.1 & 85 & 48.9 & & \\
\hline \multicolumn{7}{|l|}{ Knowledge } \\
\hline High & 56 & 42.7 & 75 & 57.3 & $0.65(0.36-1.15)$ & 0.187 \\
\hline Low & 39 & 53.4 & 34 & 46.6 & & \\
\hline \multicolumn{7}{|l|}{ Attitude } \\
\hline Negative & 57 & 52.8 & 51 & 47.2 & $1.71(0.98-2.98)$ & 0.081 \\
\hline Positive & 38 & 39.6 & 58 & 60.4 & & \\
\hline \multicolumn{7}{|l|}{ Self-efficacy } \\
\hline High & 71 & 78.9 & 19 & 21.1 & $14.01(7.1-27.5)$ & 0.001 \\
\hline Low & 24 & 21.1 & 90 & 78.9 & & \\
\hline
\end{tabular}

Table 4 The most dominant factors that affect maternal breastfeeding satisfaction

\begin{tabular}{lll}
\hline Variables & $p$ value & OR 95\% Cl \\
\hline Breastfeeding self-efficacy, $^{a}$ & 0.000 & $16.64(7.6-35.9)$ \\
Household income $^{\text {b }}$ & 0.001 & $4.63(1.8-11.2)$ \\
Education $^{c}$ & 0.037 & $2.7(1.1-7.1)$ \\
Attitude $^{d}$ & 0.046 & $2.13(1-4.5)$ \\
Delivery type $^{\mathrm{e}}$ & 0.002 & $0.21(0.05-0.54)$
\end{tabular}

a High vs. low

${ }^{\mathrm{b}}$ Below minimum standard vs. above minimum standard

'Low vs. high

${ }^{\mathrm{d}}$ Negative vs. positive

${ }^{\mathrm{e}}$ Major surgery vs. normal (per vaginal)
The results of this research also show that most of the respondents experience low satisfaction in breastfeeding (46.6\%). It is possible that the young adult respondents need guidance for breastfeeding and are primipara without prior experience in the breastfeeding. A minority had undergone caesarean sections, and lactation was not promptly initiated. Also, low breastfeeding satisfaction may have been caused by problems which arose from breastfeeding itself. The most common problems are a scarcity of breast milk and mothers having to work [18]. Besides this, mothers with breastfeeding problems tend to be less satisfied with breastfeeding but are more satisfied with their identity and lifestyle [9]. 


\section{Factors associated with breastfeeding satisfaction}

Based on statistical testing, there is an association between household income and breastfeeding satisfaction. Some respondents earn below the regional minimum wage. There is a possibility that an association between socio-economic status and breastfeeding is complex, and the difference between these aspects can be tied in with low knowledge about breast milk or feeding, negative attitudes, and no prior feeding experience. However, this research does not support this, in that it suggests that there is no association between household income, education and breastfeeding [19].

The reasons of the mothers with low household income to choose to breastfeed are natural and best for the infant, it improves the health of the mother and child, it is easy to do, and it can enhance the motherchild bonding [20]. Nonetheless, this research does not support these claims but rather states that mothers with higher household income or with better-educated partners, and mothers who have a partner and who are employed are more likely to breastfeed than mothers whose partner or themselves are unemployed [21].

The delivery-type showed association with breastfeeding satisfaction. High breastfeeding satisfaction in a normal delivery may occur because the mother can initiate early breastfeeding. Early breastfeeding initiation is the first step in breastfeeding success. This result rebuts those who state that there is no association between caesarean section and breastfeeding completion and duration, as put forward by Shawkey and Abalkhail [22]. Support for this rebuttal is given by Scott et al.'s prospective cohort research [23] on 1,059 Australian women identifying the influential factors in breastfeeding initiation and duration. They found no association between delivery type and breastfeeding, in that mothers in Australia who underwent caesarean section tended to breastfeed longer compared to those who gave normal delivery [23].

Self-efficacy is associated with breastfeeding satisfaction and is one of the crucial factors in breastfeeding [24]. Mothers who are breastfeeding confidently at the beginning of the post-partum stage tend to do it for longer and have higher self-efficacy in exclusive breastfeeding [25]. These results indirectly provide this interpretation since most of the participant who breastfed for more than 6 months had children already. The results are agreed by Febrianan [26], who claims that there is a relationship between the number of children a woman has education level and experience of breastfeeding and self-efficacy. Self-efficacy or self-confidence is a psychological factor identified as a significant predictor of intention, duration, and exclusivity of breastfeeding [25].

\section{Influencing factors of breastfeeding satisfaction}

Self-efficacy is a dominant factor influencing breastfeeding satisfaction. It is possible that the mothers have prior experience and feed for a long duration are aware of the importance regarding physical and psychological benefits of breastfeeding for their infants and themselves. The confidence and the perception of the mother about the infant feelings of satisfaction during feeding support breastfeeding successfully. It is also the most important determining factors in exclusive breastfeeding [27]. Additionally, selfefficacy supports initiation and duration [28].

Household income also affects breastfeeding satisfaction. Most mothers in this study did not work. Nonworking mother has more time with their infants and can breastfeed to meet their infants' demands. Mothers who frequently breastfeed can maintain milk production and gain direct benefits for their infants and themselves. Household income is one of the factors that contribute to maintaining intention [29]. The results of the research are congruent with researchers who state that the mother's age, education, family type, family income, and employment status are demographic and social factors that influence initiation and duration of breastfeeding [30].

Another influencing factor in breastfeeding satisfaction is education. Education has a positive impact on breastfeeding because mothers are provided with information on breastfeeding and the application of best practice. The mother's education is considered to be the most significant factor in the practice of exclusive breastfeeding [30]. In line with the study aforementioned, a high level of education is also the most strongly determining factor for initiation of breastfeeding. Meanwhile, higher parity is the most crucial factor in the continuation of breastfeeding [31].

Similarly, attitude affects satisfaction. A negative attitude is possibly linked to the duration of breastfeeding. Some respondents usually breastfeed for 6 months or more and decided to provide formula as a supplement for nutrition. Attitude is a key determinant of behaviour and a positive attitude towards breastfeeding is required to start and maintain its practice [32]. Furthermore, it is an influential factor for successful breastfeeding in the first 3 months after birth [15].

Delivery types also affect breastfeeding satisfaction. The results highlight that the majority of the respondents gave birth naturally (vaginally). Normal delivery provides greater opportunities for breastfeeding and direct mother-infant contact, as well as combined nursing care. Delivery type is independently predicted to have effects on the duration of breastfeeding, and breastfeeding self-efficacy. It also contributed to formula supplementing in hospitals [33].

\section{Limitations of the study}

This study is a cross-sectional research study in which independent and dependent variables were evaluated simultaneously without a follow-up procedure. It does 
not describe events experienced by the mothers before the study regarding breastfeeding success or problems that may have affected their breastfeeding satisfaction. Therefore, it does not disclose the causes and effects of high or low maternal breastfeeding satisfaction.

\section{Nursing implications}

This study emphasizes the importance of maternal breastfeeding satisfaction of the completion of its provision, especially for the self-efficacy of mothers. Breastfeeding self-efficacy is not the only factor that affects maternal breastfeeding satisfaction and the decrease in exclusive breastfeeding in Indonesia. However, mothers who have breastfeeding self-efficacy receive psychological benefits. They are aware that breastfeeding is important and they have a strong commitment to breastfeeding their infants. Expectant mothers with high incomes can be provided with a choice or guidance and motivation to give birth at maternity hospitals and other places that support consistent breastfeeding.

Nurses or other healthcare professionals can provide information about breast milk or breastfeeding suitable for the comprehension or education level of the information recipient, to foster willingness as well as positive attitudes towards breastfeeding. In maternity wards, healthcare professionals should provide differentiated procedures for early breastfeeding initiation for the various types of delivery (caesarean section or per vaginal). As healthcare professionals, nurses have a significant role to play in continuously encouraging exclusive breastfeeding and conveying information to the public about its importance regarding both physical and psychological benefits.

\section{Conclusion}

Breastfeeding satisfaction is the satisfying feeling obtained during breastfeeding resulting from cooperation between the mother and the infant to fulfil desires or needs. It elevates the hormones oxytocin and prolactin, resulting in the formation of the bond between the mother and infant and promoting happiness which is beneficial for mental and emotional health. Satisfaction in breastfeeding mothers cannot stand alone because there are external and internal influencing factors in play. In this research, it was found that these factors consist of breastfeeding self-efficacy $(\mathrm{OR}=16.581)$, household income $(\mathrm{OR}=4.6)$, education $(\mathrm{OR}=2.732)$, attitude $(\mathrm{OR}=2.135)$ and delivery type $(\mathrm{OR}=0.174)$.

Guidance in lactation by healthcare professionals and breastfeeding counsellors during the seven pre- and post-natal contacts must be implemented for the mother to obtain early information about breast milk and feeding. In maternity training, lactation management knowledge and skills should be developed especially regarding psychological benefits for the mother and the infant. One of the psychological benefits of breastfeeding is satisfaction. This condition indirectly motivates the mother to continue breastfeeding for up to two or more years. The author also recommends further study using different designs and methods with the same instruments to obtain a description of the results in achieving the mother's role, satisfaction in the mother's lifestyle and the infant's satisfaction, as components of maternal breastfeeding satisfaction.

\section{Abbreviations}

BSES-SF: Breastfeeding self-efficacy scale-short form; IIFAS: Infant feeding attitude scale; MBFES: Maternal breastfeeding evaluation scale; UNICEF: United Nations Children's Fund

\section{Acknowledgments}

The authors would like to thank for Directorate of Research and Community Engagement Universitas Indonesia, Nursing Study Program Jenderal Achmad Yani, Institute of Health Science.

\section{About this supplement}

This article has been published as part of BMC Nursing Volume 18 Supplement 1, 2019: Selected articles from the 6th Biennial International Nursing Conference. The full contents of the supplement are available online at https:/bmcnurs.biomedcentral.com/articles/supplements/volume-18-supplement-1.

\section{Authors' contributions}

SNA, INR, and HR designed the study, SNA collected the data, SNA, INR, and HR analysed and interpreted the data, and drafted the manuscript; SNA and INR assisted in the statistical analysis and contributed to the final manuscript. All authors read and approved the final manuscript.

\section{Funding}

The publication cost of this article was funded by PITTA UI Grant No 380/ UN2.R3.1/HKP.05.00/2017.

Availability of data and materials

Detailed data will not be shared due to the confidential nature of the data.

Ethics approval and consent to participate

The study reported in this manuscript was approved by The Ethical Committee of Faculty of Nursing No. 202/UN2.F12.D/HKP.02.04/2017,

Universitas Indonesia. All respondents signed the informed consent after a thorough explanation of the study was given.

Consent for publication

Not applicable.

\section{Competing interests}

The authors declare that they have no competing interests.

\section{Publisher's Note}

Springer Nature remains neutral with regard to jurisdictional claims in published maps and institutional affiliations.

\section{Author details}

${ }^{1}$ The Institute of Health Science Jenderal Achmad Yani, Cimahi, West Java 40633, Indonesia. ${ }^{2}$ Master of Nursing Program, Faculty of Nursing, Universitas Indonesia, Jalan. Prof. Dr. Bahder Djohan. Kampus UI Depok, Depok, West Java 16424, Indonesia. ${ }^{3}$ Department of Maternity and Women's Health, Faculty of Nursing, Universitas Indonesia, Jalan. Prof. Dr. Bahder Djohan. Kampus UI Depok, Depok, West Java 16424, Indonesia. 
Published: 16 August 2019

\section{References}

1. World Health Organization (WHO). Global Nutritions targets 2025 breastfeeding policy brief. Switzerland: Departement of Nutrition for Health and Development World Health Organization; 2014.

2. Unite for Children (UNICEF) Indonesia. Laporan Tahunan Indonesia 2014 Jakarta: UNICEF; 2014.

3. Survei Demografi dan Kesehatan Indonesia (SDKI). Survei Demografi dan Kesehatan Indonesia 2012. Jakarta: SDKl; 2013.

4. Doyle N. "The highest pleasure of which Woman's nature is capable": breast-feeding and the sentimental maternal ideal in America, 1750-1860. J Am Hist. 2011:97(4):958-73. https://doi.org/10.1093/jahist/jaq050.

5. Phillips KF. First-time breastfeeding mothers: perceptions and lived experiences with breastfeeding. Int J Childbirth Educ. 2011;26(3):18-22.

6. Hall WA, Hauck Y. Getting it right: Australian primiparas' views about breastfeeding: a quasi-experimental study. Int J Nurs Stud. 2007;44(5):78695. https://doi.org/10.1016/j.jinurstu.2006.02.006.

7. Lee EJ. Living with risk in the age of 'intensive motherhood': maternal identity and infant feeding. Health Risk Soc. 2008;10(5):467-77. https://doi. org/10.1080/13698570802383432

8. Fikawati S, Syafiq A. Kajian implementasi dan kebijakan air susu ibu eksklusif dan inisiasi menyusu dini di Indonesia. Makara kesehatan. 2010;14(1):17-24.

9. Cooke M, Sheehan A, Schmied V. A description of the relationship between breastfeeding experiences, breastfeeding satisfaction, and weaning in the first 3 months after birth. J Hum Lact. 2003:19(2):145-56. https://doi.org/1 $0.1177 / 0890334403252472$

10. Thulier D, Mercer J. Variables associated with breastfeeding duration. J Obstet Gynecol Neonatal Nurs. 2009;38(3):259-68. https://doi.org/10.1111/ j.1552-6909.2009.01021.x.

11. Kim SH. Factors explaining Mothers' breastfeeding satisfaction. Korean J Women Health Nurs. 2009;1, 15(4). https://doi.org/10.4069/kjwhn.2009.15.4.270.

12. Dinas Kesehatan Kota Bandung. (2012). Profil Kesehatan Kota Bandung Tahun 2012.http://www.depkes.go.id/resources/download/profil/PROFIL_ KAB_KOTA_2012/3273 Jabar_Kota_Bandung_2012.pdf.

13. Kemenkes RI. Profil Kesehatan Indonesia 2015. Jakarta: Kementrian Kesehatan Rl; 2016.

14. Labarère J, Gelbert-Baudino N, Laborde L, Baudino F, Durand M, Schelstraete C, François P. Determinants of 6-month maternal satisfaction with breastfeeding experience in a multicenter prospective cohort study. J Hum Lact. 2012;28(2):203-10. https://doi.org/10.1177/0890334411429114.

15. Tarkka M, Paunonen $M$. Factors related to successful breastfeeding by firttime mothers when the child is 3 months old. Nursing. 1999:29(1):113-8.

16. Kronborg $H$, Vaeth $M$. The influence of psychosocial factors on the duration of breastfeeding. Scand J Public Health. 2004;32(3):210-6.

17. Gregory EF, Butz AM, Ghazarian SR, Gross SM, Johnson SB. Met expectations and satisfaction with duration: a patient-centered evaluation of breastfeeding outcomes in the infant feeding practices study II. J Hum Lact. 2015;3(3):444-51. https://doi.org/10.1177/0890334415579655.

18. Perkumpulan perinatologi Indonesia (Perinasia). Manajemen Laktasi. Jakarta: Perinasia; 2016.

19. Sarbini D, Hidayati L. Hubungan antara tingkat pendapatan keluarga dan pendidikan ibu dengan pemberian asi eksklusif di kecamatan jebres kotamadya surakarta. Kesehatan, I No. 2(ISSN 1979-7621); 2008. p. 115-22. Retrieved from publikasiilmiah.ums.ac.id

20. Alexander A, Dowling D, Furman L. What do pregnant low-income women say about breastfeeding?. Breastfeeding medicine. Vol. 2010;5(1):17-23. https://doi.org/10.1089/bfm.2009.0034.

21. Heck KE, Braveman P, Cubbin C, Chavez G, Kiely J. Socioeconomic status and breastfeeding initiation among California mothers. Public Health Rep. 2006;121:51-9.

22. Shawky S, Abalkhail BA. Maternal factors associated with theduration of breast feeding in Jeddah, Saudi Arabia. Paediatr Perinat Epidemiol. 2003;17: 91-6. https://doi.org/10.1046/j.1365-3016.2003.00468.x.

23. Scott JA, Landers MCG, Hughes RM, Binns CW. Factors associated with breastfeeding at discharge and duration of breastfeeding. J Paediatr Child Health. 2001;37:254-61. https://doi.org/10.1046/j.1440-1754.2001.00646.x.

24. Mulyati, S. \& Waluyanti, F. (2013). Gambaran Self-efficacy Menyusui Pada Ibu Postpartum Dalam Memberikan ASI eksklusif pada bayi Di RS Medistra Jakarta. Retrieved from lib.ui.ac.id
25. Bosnjak P, Rumboldt M, Stanojevic M, Dennis CL. Psychometric assessment of the Croatian version of the breastfeeding self-efficacy scale-short form. J Hum Lact. 2012;28:565-9. https://doi.org/10.1177/0890334412456240.

26. Sukmawati DP, Rachmawati IN. Maternal Psychosocial Condition Affect on Breastfeeding Self-Efficacy in Pregnant Teenager, UI Proceedings on Health and Medicine; 2017. p. 2. https://doi.org/10.7454/uiphm.v2i0.154.

27. Kurniawan B. Determinan keberhasilan pemberian air susu ibu eksklusif. Jurnal Kedokteran Brawijaya. 2013;27(4):236-40.

28. Keemer F. Breastfeeding self-efficacy of women using second-line strategies for healthy term infants in the first week postpartum: an Australian observational study. Int Breastfeed J. 2013:8:18 1-8. Retrieved from http://www.internationalbreastfeedingjournal.com/content/8/1/18. https://doi.org/10.1186/1746-4358-8-18 page.

29. Persad MD, Mensinger JL. Maternal breastfeeding attitudes: association with breastfeeding intent and socio-demographics among urban primiparas. J Community Health. 2008;33(2):53-60. https://doi.org/10.1007/s10900-007-9068-2.

30. Dubois L, Girard M. Social determinants of initiation, duration, and exclusivity of breastfeeding at the population level: the results of the longitudinal study of child development in Quebec (ELDEQ 1998-2002). Canadian J Public Health. 2003;94:300-5 http://www.jstor.org/stable/41 993668.

31. Bunschoten AMW, Van Bodegom S, Reerink JD, Jong P, Groot C. Reluctance to continue breastfeeding in the Netherlands. Acta Pediatre. 2001;90:104753. https://doi.org/10.1111/j.1651-2227.2001.tb01362.x.

32. Saied H, Mohamed A, Suliman A, Anazi W, et al. Breastfeeding knowledge, attitude and barriers among Saudi women in Riyadh. J Nat Sci Res. 2013; 3(12):6-13 Retrieved from https://www.iiste.org/Journals/index.php/JNSR/ article/view/8501/8440

33. Semenic S, Loiselle C, Gottlieb L. Predictors of the duration of exclusive breastfeeding among first-time mothers. Res Nurs Health. 2008;31(5):428-41. https://doi.org/10.1002/nur.20275.

Ready to submit your research? Choose BMC and benefit from:

- fast, convenient online submission

- thorough peer review by experienced researchers in your field

- rapid publication on acceptance

- support for research data, including large and complex data types

- gold Open Access which fosters wider collaboration and increased citations

- maximum visibility for your research: over $100 \mathrm{M}$ website views per year

At $\mathrm{BMC}$, research is always in progress.

Learn more biomedcentral.com/submissions 